\title{
BARTLEBY NO CINEMA: CORPO ESPECTRAL E TECNOLOGIA DA IMAGEM
}

\author{
BARTLEBY EN EL CINE: CUERPO ESPECTRAL Y \\ TECNOLOGÍA DE LA IMAGEN
}

Rita Lenira de Freitas Bittencourt*

Resumo: A partir da leitura de "Bartleby, the Scrivener - a story of Wall Street", conto do escritor norte-americano Herman Melville (1817-1891), do levantamento de suas montagens, para cinema e TV, e da análise de uma delas, de 2001, este artigo pretende refletir brevemente sobre a cena contemporânea, considerando algumas teorias da imagem e os impasses de passagem da literatura ao cinema.

PALAVRAS-CHAVE: Literatura. Cinema. Imagem. Bartleby. Melville.

Resumen: Desde la lectura de "Bartleby, the Scrivener - a story of Wall Street", cuento del escritor norte-americano Herman Melville (1817-1891), del elenco de sus montajes, para cine y televisión, y también partiendo de la análisis de una de ellas, hecha en 2001, este articulo piensa brevemente la cena contemporánea, considerando algunas teorías de la imagen y los impases de pasaje de la literatura al cine.

Palabras-Llave: Literatura. Cine. Imagen. Bartleby. Melville.

Sospechava que el cine era el arte más engañoso de todos y el único en el que nunca nada era cierto. Enrique Vila-Matas, Nunca voy al cine, 1982, p.18.

1. Bartleby

A personagem Bartleby pertence a um dos contos mais famosos do século 19, "Bartleby, the scrivener - a story of
Wall Street", do escritor norte-americano Herman Melville. O conto foi publicado pela primeira vez em 1853, na revista Putnam's, de Nova Iorque, dividido em duas edições, a de novembro e a de dezembro.

Sua fama, entretanto, é tardia. Apenas as primeiras narrativas de Melville, de caráter romântico, descrevendo aventuras marítimas, obtiveram a admiração do público.As demais, mesmoa mais conhecida, Moby Dick, não alcançaram, em sua época, o

\footnotetext{
* Professora adjunta de Teoria da Literatura na Universidade Federal do Rio Grande do Sul. Professora no PPGLet área Literatura Comparada.E-mail:<rita.lenira@ufrgs.br>.
} 
sucesso esperado, e o escritor, desiludido e empobrecido, acabou aposentando-se, num cargo de fiscal portuário da alfândega, e morreu no mais completo anonimato em 1891. Há quem afirme que Melville foi Bartleby - um estranho escriturário, que se recusa a cumprir as ordens que lhe são dadas-, antes de escrevê-lo'.

Atualmente, Bartleby e Moby Dick trouxeram Melville de volta, fazendo aparecer os contornos de uma escritura singular, deslocada no seu tempo, pois propunha uma visão da literatura em chave teórica moderna e antecipava os enigmas e as discussões formais do século 20 . Por sua configuração espectral, reticente e catatônica, a personagem Bartleby, especialmente, irá alimentar os estudos das artes visuais, em relação à predominância e à especificidade de seus meios, e também as pesquisas experimentais, que conjugam linguagem e imagem.

Contemporâneo de Melville, o cinema caracteriza-se, basicamente, pela estética fragmentária, que, através de cortes e disjunções, produz uma trama visual mais vinculada à heterogeneidade do mundo moderno e auxilia na configuração de uma sensibilidade estruturada por choques e por rupturas espácio-temporais, como bem

1 Como o escritor espanhol Enrique Vila-Matas, por exemplo, autor de Bartleby \& Compañia (Barcelona: Editorial Anagrama, 2000), uma narrativa que se estrutura por notas de pé de página, elaboradas por um corcunda, que comentariam um texto invisível. $O$ narrador acredita que Melville tornou-se vítima do que ele denomina de "síndrome de bartleby" - uma profunda atração pelo "nada", responsável pela produção do que ele denomina de "literatura do Não" - antes mesmo de este personagem existir. Melville teria sido, então, o primeiro Bartleby, o fundador desta estranha companhia de escritores. apontou, ao analisá-lo em seus primórdios técnicos, o teórico Walter Benjamin.

Ao desenrolar, a partir de um fio bartlebiano, uma reflexão sobre a visualidade, tento abordar as transformações trazidas pelas experiências de dilaceramento do sujeito, provocadas, especialmente, pela conexão entre a guerra e o advento da técnica, tomada em tempos superpostos - de Melville, das vanguardas, da alta modernidade -, e que se desdobram, anacronicamente, no presente. Além destas passagens temporais, nada tranquilas, é preciso pensar outra, que vai da literatura ao cinema, e, ainda, a partir das teorias da imagem, entender uma forma artística que se dá por negação e por ausência. Os elementos da "teoria do Não" têm sido o suporte básico da produção visual de todos os tempos, mas tornaram-se o foco das discussões na pós-modernidade.

Antes, porém, é preciso citar alguns desdobramentos cinematográficos do texto literário.

\section{NO CINEMA}

A deriva bartlebiana, que utiliza "Bartleby, the scrivener - a story of Wall Street" como argumento, para produzir trabalhos visuais, é surpreendentemente rica e proliferante. Passa pela TV e pelo cinema, de curta e longa duração, e vai desde o campo experimental até o âmbito mais comercial.

No texto de apresentação da tradução do conto para o português, publicada no início da década de 1970, Olívia Krähenbüld, em artigo introdutório, comenta o retorno a Melville e a amplitude deste interesse: 
Herman Melville começou a ressurgir entre 1924 e 1945; mas em 1960, nenhum autor, em toda a literatura norte-americana, era estudado com maior afinco ou mais ardente entusiasmo do que ele - da França à Alemanha, do Japão à Áustria, dos Estados Unidos à Austrália. A crítica moderna considera, dentre os contos, "Bartleby" e "Benito Cereno" autênticos triunfos literários. Ainda recentemente, nos Estados Unidos, "Bartleby" foi dramatizado e difundido com êxito pela televisão. Mas acredita-se que, em sua maior parte, os leitores do conto e seus fãs de vídeo não chegaram a inteirar-se do motivo para tal preferência: a obstinação do protagonista em afirmar a sua natureza individual, recusando-se, por meio da resistência passiva (no que se é levado a pensar em Thoreau, Gandhi e outros exemplos) a aceitar o insatisfatório estado do mundo. (KRÄHENBÜLD, 1969, p.28).

Associando as atitudes da personagem ao pensamento político, bem aos moldes daqueles anos, a tradutora menciona um quase lugar-comum, hoje, nas muitas análises críticas de Bartleby: a resistência passiva, algo que, de algum modo, vinha ao encontro dos desejos de superação de políticas e/ou regimes autoritários, seja nos EUA, com o fim da intervenção no Vietnã, seja na América Latina, com o crescimento e avanço das reações às ditaduras militares.

Antes, porém, desta versão televisiva norte-americana, citada por Olívia Krähenbüld, houve outra, feita com uns vinte anos de antecedência, para a TV francesa, na qual o personagem principal adquire o prenome "Pierre-Jacques":

\section{Bartleby L'écrivain (1957)}

Direção: Claude Barma

Adaptação: Jacques Armand

Elenco: Pierre Moncorbier (como Pierre-Jacques Bartleby), Louis Seigner, Paul Préboist, Jean Bellanger, Léonce Corne, Marcel Carpentier, Jean Ozenne e Jean Berger².

As informações a respeito destas montagens para a TV são escassas e desencontradas, mas as versões cinematográficas, por serem mais recentes, contam, na Internet, com alguns comentários e releases, de conteúdo crítico, embora predominem as descrições com o objetivo de promover a venda dos filmes, em cópias DVD ou VHS. Desconheço um estudo especializado, de crítica cinematográfica, sobre a filmografia de Bartleby. Com alguma sorte, às vezes se consegue acessar, nos endereços virtuais que tratam de cinema, descrições de cenas e raras análises pontuais.

Há uma produção inglesa bastante elogiada, considerada ao mesmo tempo dramática, engraçada, irônica e provocadora de perplexidade:

\author{
Bartleby (1970) \\ Direção: Antony Friedman \\ Adaptação escrita do conto de Melville: \\ Rodney Carr-Smith e Anthony Fried- \\ man \\ Gênero: Drama \\ Elenco: Paul Scofield, John MacEnery
}

2 Ver <http://www.filmcritic.com/>. 
(Bartleby), Thorley Wlaters, Colin Jeavons, Raymond Mason, Charles Kinross, Neville Barber, Robin Askwith, Hope Jackman, John Watson, Christine Dingle, Rosalind Elliot e Tony Parkin.

Duração de 78 minutos.

País: Inglaterra ${ }^{3}$

Segundo Roger Greenspun 4 , o diretor Anthony Friedman move a ação do filme, de Nova Iorque, 1850, para Londres, 1970. E transforma a atividade do copista na de bibliotecário. A personagem Bartleby anda pela cidade, em seu tempo livre, tem um pouco de vida pessoal e transmite algo a respeito dos seus pontos de vista, o que não ocorre no conto de Melville, no qual a sua subjetividade e os seus dados de identificação permanecem incógnitos.

O crítico considera que estas mudanças, embora pareçam dar um tratamento inapropriado ao texto original, fazem com que o filme tenha o senso, ou a inocência, de fazer de si mesmo algo mais. Este "algo mais", que torna Bartleby um alienado moderno e, ironicamente, inglês, revela-se eficaz. O bibliotecário senta-se à sua mesa e prefere não trabalhar; depois, prefere não se mover, até que a sua preferência chega à absoluta discrição da morte, conservando muito do seu enigma.

A partir da descrição de algumas sequências, pode-se ter uma ideia das diferen-

3 Cf. <http://query.nytimes.com/search/articleprintpage.html>.

4 No artigo "Melville's 'Bartleby' transformed for the screen", de 7 de janeiro de 1972, que, junto com a ficha técnica do filme, pode se acessado na página citada na nota anterior. ças com relação ao texto de Melville, nas quais, paradoxalmente, sem traição, se define a materialidade filmica proposta por Friedman. Com relação aos atores, o olhar arguto do crítico percebe um trabalho cuidadoso, de quem se identifica com os personagens não apenas pelo que eles têm de evidente, enquanto tipos singulares, mas pelo que assinalam para além do conto, pelo que deixam em suspenso no espaço cenográfico.

Um longa-metragem francês, com o mesmo título, também desloca a ação, só que, desta vez, de Nova Iorque, nos anos 1850, para Paris, nos anos 1970. O filme é inicialmente produzido, em 1976, para a rede de televisão Antena 2. Mais tarde, sofre adaptação para o cinema, tendo um conhecido ator de comédias no papel de Bartleby:

Bartleby (1978)

Direção: Maurice Ronet

Adaptação de Melville: Yvan Bostel

Gênero: Drama

Elenco: Michael Lonsdale, Maxence Mailfort (Bartleby), Maurice Biraud, Dominique Zardi, Jacques Fontanelle, Hubert Deschamps, Albert Michel, Philippe Brigaud, Michel Fortin, Bruno Balp, Hervé Le Boterf, Florence Blot, Simone Chatelain, Henri Attal e Serge Bento.

Duração: 96 minutos

País: França

Colorido 5 .

Ainda na França, a romancista e roteirista Véronique Tacquin, seis anos depois, exibe o experimental Bartleby ou Les Hommes au rebut:

5 Ver $<$ http: $/ /$ www.filmcritic.com/>. 


\author{
Bartleby ou Les hommes au rebut \\ (1993) \\ Direção e Roteiro: Véronique Tacquin \\ Fotografia: Alain Levent \\ Elenco: Daniel Gélin, Manuel Gélin, \\ Marc Dudicourt, Jean-François \\ Perrier, Hugues Quester \\ 34 minutos \\ Sépia Productions, $16 \mathrm{~mm}$ \\ Preto e branco ${ }^{6}$
}

Um curta-metragem australiano, bastante premiado em $2001^{7}$, leva as referências a Melville para além do espaço de leitura americana ou europeia, a partir da adaptação de um conhecido diretor, roteirista e crítico de cinema:

\section{Bartleby (2000)}

Direção e roteiro: Miro Bilbrough

Gênero: curta

País: Austrália ${ }^{8}$

Voltando à referência inicial, a série cômica "Bartleby", exibida pela TV americana, na década de 1970, é importante mencionar que ela vai dar origem, em 2001, a um longa-metragem, para cinema:

\section{Bartleby (2001) \\ Produção e Direção: Jonathan Parker \\ Roteiro: Jonathan Parker e Catherine di Napoli \\ Direção de Fotografia: Wah Ho Chan \\ Edição: Rick LeCompte}

\footnotetext{
6 Ver <http://www.uhb.fr/alc/cellam/soi-disant/o4Au teurs/Veronique-T.html>

7 O filme recebeu Certificado de Mérito, no Festival Internacional de São Francisco, EUA; Prêmio de Distinção da Sociedade Cinematográfica Australiana; Segundo Lugar, Categoria Curtas, no Festival Internacional de Bilbao de Documentários e Curtas, Espanha, 2001.

8 Ver <http://query.nytimes.com/search/article>.
}

\author{
Música: Jonathan Parker e Seth \\ Asarnow \\ Produção de desig: Rosario Provenza \\ Realização: Parker Film Company \\ Duração: 82 minutos. \\ Elenco: David Paymer, Crispin Glover \\ (Bartleby), Glenne Headly, Joe Piscopo, \\ Maury Chaykin, Seymour Cassel, \\ Carrie Snodgress e Dick Martin. \\ País: EUA \\ Colorido 9
}

Esta montagem recebeu várias críticas à direção, que apela para uma saturação dos sentidos, na qual os elementos técnicos redundam os diálogos, que repetem, palavra por palavra, trechos do conto de Melville, o que, associado à trilha sonora, acaba provocando certo tédio.

Por outro lado, é um trabalho exemplar, se tomado em relação a alguns aspectos da cinematografia contemporânea, como a noção de corpo espectral, por exemplo, desenvolvida pelo filósofo, dramaturgo e romancista francês Alain Badiou, que me interessa discutir.

Sem a intenção de "contar o filme" em palavras, passo a descrever algumas cenas e a tecer alguns comentários de cunho geral, para, a partir daí, retornar às reflexões teóricas.

\section{3. ЕM 2001}

Pensando num tipo convencional de roteiro, no qual os elementos são expressos

9 Página do Film Festival Review, que aconteceu no Museu de Arte moderna de Nova Iorque, assinada por A. O. Scott, em 23 de março de 2001. 
dramaticamente dentro de uma sequência definida, com início, meio e fim, incorporando uma ordem substantiva, isto é, pressupondo que se trata de um personagem, ou de personagens, num lugar ou lugares, vivendo a sua "coisa", que é a própria ação, percebe-se que a adaptação de Jonathan Parker se ajusta muito bem a este modelo, tendo, inclusive, a preocupação inicial de deixar evidente a sua origem literária.

Antes de o filme ter propriamente iniciado, uma fotografia de Melville, sobre um fundo preto, é exibida na tela, como efígie, acompanhada de uma pequena biografia escrita, dividida em três partes. Em seguida, entram os créditos, na seguinte ordem: o chefe do escritório, sem nome (David Paymer) e o funcionário Bartleby (Crispin Glover) apresentam o título do filme: "Bartleby"; depois, aparecem os demais personagens e os nomes dos atores, e se cita a equipe técnica. A música, que será a marca mais evidente do personagem principal, de autoria de Jonathan Parker e Seth Asarnow, entra junto com a abertura, feita em computação gráfica: uma espécie de espiral, em roxo, que faz girar as imagens, como fotos recortadas, e também os nomes. Este efeito antecipa tanto a palheta de cores e as escolhas estéticas da direção de arte do filme, quanto à trilha sonora, cuja repetição será dominante e, por isso, alvo de muitas críticas. A trilha sonora é repetitiva, funcionando como uma espécie de "hino" bartlebiano de todos os trabalhadores deslocados, o que não a impede de ser incrivelmente irritante.

Nos primeiros segundos, vê-se o personagem principal, corretamente vestido, de terno escuro, gravata e camisa branca, atravessando a pé uma espécie de passarela, que é toda metálica e ocupa o espaço inteiro da tela. O personagem encosta-se a ela, e o seu corpo assim, com os braços semiabertos, meio que crucificado por uma grade de arame, se desenha nas bordas da passarela, sobre uma rodovia. A imagem congela. Em seguida, o seu futuro chefe, de carro, passa logo abaixo e aí começa a sua apresentação. Vemos a sua posse, como diretor do arquivo público, e ele mesmo diz ser do ramo de negócios de administração de arquivos. Diferente do personagem melvilliano, que era um antigo advogado, este, ainda jovem, é um especializado guardador de memória.

O conto de Melville inicia justamente com a fala do advogado, que narra a história. Parker parece ter sentido necessidade de apresentar Bartleby antes, e cria a sequência inicial, antecipando os dados que Melville desenrolará ao longo do texto: anuncia a solidão, apresenta Bartleby fisicamente, e desenha a insularidade material e psicológica, em relação ao mundo, na qual ele se move. Os primeiros minutos do filme vão, junto com a abertura, portanto, criar o "clima" no qual este se desenvolverá.

O escritório é apresentado como um edifício quadrado, uma espécie de pirâmide desenhada em computação gráfica, situado num platô, cercado por múltiplas rodovias, com acesso difícil para pedestres. Sem janelas, pintado em verdes, amarelos e distintos tons de marrom, tem as paredes decoradas com paisagens enormes e falsas, mostrando florestas e veadinhos, que não impedem que se receba, de fora, a impressão barulhenta do lixo sendo recolhido, ou que o prédio seja sacudido, em alguns momentos, por uma 
vibração sutil, que se torna uma constante ameaça de desmoronamento. A entrada e a saída de ar se dão pelo teto, por uma espécie de exaustor que irá adquirindo um enfoque especial no decorrer do filme.

As três personagens de Melville são conservadas, embora sofram modificações: Turkey vira Ernie, um funcionário lento, gordo e atrapalhado vivido por Maury Chaykin; Nippers é Rocky, um homem forte e um tanto violento, vivido por Joe Piscopo; e Ginger Nut, que em Melville é um menino de 12 anos, torna-se Vivian, uma secretária sonsa, sempre vestida de tailleurs vermelhos, vivida por Glenne Headly. Com Vivian, a história toma outros rumos, pois além dela manter um tipo de rivalidade com Bartleby, participa de um jogo sedução, nunca levado a termo, com o superior de todos, Mr. Waxman, vivido por Seymor Cassel. Para Bartleby, quando este responde a um anúncio e vai trabalhar no escritório, ela mostra a saída de ar do teto, afirmando que dali se pode ouvir o oceano. Este objeto se tornará o ponto de atração do personagem, que irá voltar-se cada vez mais para ele, permanecendo em pé, olhando-o fixamente, num alheamento crescente e perturbador.

A confrontação, ou o conflito, é introduzido pela primeira negativa de Bartleby em cumprir uma ordem do chefe, recebida com estranheza por todos, e segue num crescendo até a mudança de escritório, a última saída, para o personagem de David Paymer, já desesperado com a situação, que se livra de Bartleby por um tempo, deixando-o, como uma mobília, para que os próximos ocupantes da sala cuidem dele. Neste processo, muitas trapalhadas acontecem, sendo que a mais interessante e que, obviamente, está completamente fora do texto de Melville, dá-se quando Mr. Waxman, após uma costumeira cena de sedução com Vivian, se retira, e ela, em dueto com Rocky, canta uma canção, acompanhada, por Ernie, numa viola country, que tem por refrão a frase de Bartleby "I would prefer not to", e que também explora as diversas possibilidades do nome "waxman" - homem de cera - tanto para falar da indiferença e da palidez do colega, quanto para avaliar sarcasticamente as atitudes do superior. O episódio é constrangedor, tanto para Bartleby, quanto para o Mr. Waxman, que ouve a musiquinha e retorna. O chefe imediato - Paymer - acaba resolvendo a situação, que se apresenta, no filme, como o ponto alto da comicidade.

E aí talvez esteja um dos grandes problemas da direção de Parker: ele dispõe de bons atores, de tipos bem construídos, de uma boa história, e de um cenário especialmente criado para que a comicidade flua, mas a atuação de Crispin Glover, como um Bartleby triste e patético, muito próximo da de um doente, com dificuldades físicas de expressão, que inspira mais piedade do que riso faz com que os demais se tornem caricaturas um tanto ridículas. A música também contribui para um desempenho oscilante, entre o drama e a comédia, e o filme se suspende neste limiar.

No final, Bartleby é abandonado por todos, e trêmulo, sob um viaduto, se recusa a comer, a reagir, a fazer qualquer coisa, recuperando a cena da "carta morta", exibida no início, na qual Bartleby apresenta-se para 
o emprego entregando uma carta de recomendação, que menciona a sua ocupação anterior, num escritório encarregado de resolver o problema da correspondência extraviada, aquela que não chega aos destinatários. Em Melville, trata-se de um vago boato, que ajuda a construir o papel marginal do escriturário, nas linhas finais do conto. Em Parker, a "carta morta” participa de uma lógica circular, que une o começo e o fim do filme.

$\mathrm{O}$ personagem de Paymer, após pronunciar as palavras: "Ah, Bartleby! Ah, humanidade!", diante do rapaz morto, dá a entender que o filme acabou, mas Parker, como bom diretor norte-americano, acrescenta um último suspiro: corta para uma cena na qual um texto, escrito pelo personagem de David Paymer, contando a história de Bartleby, é recusado por uma editora (Carrie Snodgress), que só aparece nesta sequência. E então, como numa espécie de círculo vicioso e inevitável, o homem é capturado pela onda Bartleby e passa a repetir ininterruptamente "I would prefer not to", olhando fixamente para um condicionador de ar. A parte frontal do aparelho, uma espécie sonora de grade, é a imagem final, com a fórmula repetida soando ao fundo.

Este final, que pertence apenas ao filme, reforça as preocupações de Parker com o deslocamento temporal. Se a imagem, em computação gráfica, do escritório e dos demais prédios da cidade, é a de um não-lugar contemporâneo, o deslocamento da visão para aparelhos, como exaustores e condicionadores de ar, além de reforçar o caráter tecnológico das instâncias de poder, traz uma dimensão ainda mais cruel das limitações impostas ao ser humano pelos lugares fechados e frios, desconectados da natureza. Além disso, a certeza da impossibilidade, mesmo para um guardador da memória, de contar uma história, faz com que o estado de inadaptação, exposto em Melville, seja intensificado por Parker.

De certo modo, a inadaptação de Bartleby acaba assombrando o filme, cujo roteiro, ainda que tenha proposto inovações e atualizações, padece de uma inadaptação fundamental, entre o drama e a comédia, que funciona, por um lado, por captar com precisão a natureza complexa da literatura de Melville, mas que não funciona, por outro, como peça dramática, e se perde ao apontar, sem explorar, as suas próprias e várias possibilidades. Outro agravante é que não consegue desprender-se nem da lógica nem da sequência do relato, tornando-se uma ilustração deste, um mero suporte para o texto literário.

Alegoricamente, esta produção faz retornar o lugar-comum, sobre o cinema, que afirma que se o filme não convence como filme, ao menos dá suporte para pensá-lo, outra vez, em suas especificidades. Neste caso, a partir das instâncias do negativo, das quais a personagem Bartleby é o paradigma, pode-se entendê-lo como um corpo desconjuntado e espectral.

\section{UM CORPO ESPECTRAL}

Em uma conferência, de 1994, intitulada "Os falsos movimentos do cinema"10, o filósofo Alain Badiou afirma

Originalmente "Le cinéma comme faux mouvement". In: L’Art du cinéma, n.4, Paris, 1994. 
que "um filme funciona pelo que retira do visível" (BADIOU, 2002, p.103). Mais importantes que a presença das ideias, nas imagens, são os cortes, executados não somente pelos efeitos de montagem, como também pelos enquadramentos $\mathrm{e}$ pela depuração controlada e planejada do que se faz visível. O modo segundo o qual as coisas são aprisionadas pelo recorte cinematográfico faz com que elas, simultaneamente, se exibam como singularidades e sejam, em segundo plano, uma corporificação, distraída e visual, de uma ideia.

O cinema seria, então, uma arte que é visitada pelo passado, no sentido de que o passado se institui ao passar, mobilizando um sentido do que já se havia visto ou ouvido e que permanece enquanto passa, e que, ao mesmo tempo, tenta organizar esta passagem, do pensamento conectado ao visível, em operações cujas possibilidades são inventadas e reinventadas a partir das habilidades próprias de cada técnico e/ou artista.

Assim, o movimento, no cinema, poderia ser pensado de três modos diferentes. Por um lado, remetendo a ideia à eternidade paradoxal de uma passagem, de uma espécie de visitação e, neste caso, se trataria de um movimento global. Por outro lado, o movimento local, por meio de operações complexas, é o que subtrai a imagem de si mesma, ou o que faz com que ela, ainda que inscrita, permaneça não apresentada, porque é aí que se encarnam os efeitos do corte, especialmente quando a detenção aparente permite ver o esvaziamento do visível. Por último, o movimento impuro é a circulação, a participação na totalidade das outras atividades artísticas, em uma alusão constante, contrastante e subtrativa.

Badiou denomina de "poética do cinema" ao enredo destas três acepções da palavra "movimento", e cujo efeito é a visitação da ideia ao sensível. Insiste, entretanto, na expressão "visitação", pois o cinema desmente a tese clássica de que a arte seria a forma sensível da ideia, no sentido platônico, posto que não possui, concretamente, nenhum corpo. Não é algo separável, na prática, e não existe, no cinema, mais do que em sua passagem: a ideia é, concretamente, a própria visitação. Esta relação se explicita como um "para fora" da relação direta entre a ideia e uma cópia, em imagem, que seria secundária, pois, segundo o teórico, "o cinema é a menos mimética das artes".

O cinema faz aparecer o passar, a concretude mesma da visita, e nisto articula os três movimentos: o global, no qual a ideia nunca é mais que sua passagem; o local, pelo qual é, também, diferente de sua imagem; e o impuro, pelo qual se aloja nas fronteiras oscilantes, entre as áreas artísticas abandonadas. Assim como a poesia é uma suspensão na língua por efeito de um artifício codificado de seu manejo, os movimentos que compõem a poética do cinema são, certamente, também, artifícios, falsos movimentos ${ }^{11}$.

O movimento global é falso porque a ele nenhuma medida convém. A subestrutura

11 Alain Badiou associa os movimentos falsos, que configuram o cinema, ao filme $\mathrm{O}$ movimento falso, de Win Wenders comparando, em chave política, as duas poéticas; uma, digamos, filosófica e constituinte, e outra, artística ou prática. 
técnica regula um desfile discreto e uniforme, e toda sua arte consiste em não considerar nada mais que isso. As unidades de corte, assim como os planos ou as sequências não se compõem na medida do tempo, mas na de vizinhança, de chamado, de insistência ou de ruptura, cujo verdadeiro pensamento é uma topologia mais que um movimento. De certa forma, filtrado pelo espaço de composição, presente desde a filmagem, se impõe como o falso movimento pelo qual a ideia não está dada senão como passagem. Pode-se dizer que há ideia porque há espaço de composição, e que há passagem porque este espaço se libera, se expõe como tempo global. O movimento global torna-se, então, um estiramento pseudonarrativo de alguns lugares.

O movimento local também é falso porque é, somente, o efeito da subtração de uma imagem, que, ao subtrair acaba dizendo-se a si mesma. Aqui, tampouco, há movimento original, movimento em si. O que há é uma visibilidade que, ao não ser reprodução de nada, cria um efeito temporal de já visto, já percorrido, para que este visível, de alguma maneira, seja testemunhado "fora da imagem", pelo pensamento.

O movimento local orienta-se para o movimento impuro, que se instaura no limite entre o cinema como filme e o cinema como configuração, ou como arte; no limite entre o cinema, ele mesmo, ou como afetividade, algo do passado que parece retornar.

$\mathrm{O}$ movimento impuro, segundo $\mathrm{Ba}$ diou, é o mais falso de todos, pois não existe, na realidade, nenhum meio para que se produza a transposição de uma arte a outra. Em muitos aspectos, as artes estariam fe- chadas. Nenhuma pintura se transformaria em música, nenhuma dança em poema, e todas as tentativas diretas, neste sentido, seriam vãs. E ainda assim, o cinema é, certamente, a organização desses movimentos impossíveis. A alusão às outras artes, que o constitui, as arranca delas mesmas, e é justamente na mescla fronteiriça que se dá esta passagem como visitação, articulada por subtrações.

O cinema, nos filmes, constitui um nó de falsos movimentos, o espaço por onde vibra a mistura, a impureza que perturba. É uma arte impura, a "mais uma" das artes, parasitária e inconsistente. Mas a sua força de arte contemporânea consiste, justamente, em gerar a ideia de impureza de toda a ideia, no tempo de um passar, constituindo, como a personagem Bartleby, um corpo híbrido e de consistência espectral.

Bartleby é cinema quando se torna, por um lado, o sintoma da condição moderna, anestética e saturadora dos sentidos, reversão do excesso devolvida em hesitação e silêncio, e, por outro, quando se relaciona à noção específica do discurso cinematográfico de "operação por subtração".

Seria possível, então, aproximar a noção de "passagem" elaborada por Alain Badiou da teoria sobre a "suspensão" da linguagem, apontada, em relação à fórmula de Bartleby, pelo filósofo italiano Giorgio Agamben, que leva adiante a discussão sobre a famosa frase pronunciada pelo escriturário, I would prefer not to, nas diversas possibilidades em que ela funciona - ou não funciona -, em sua capacidade de carregar as baterias dos sentidos da transgressão e de se exibir como potência da linguagem. 
Para Agamben, a frase I would prefer not to é o anúncio exemplar da potencialidade da linguagem. "Como um escriba que parou de escrever", salienta o teórico, "Bartleby é a extrema figura do Nada da qual toda a criação deriva; e, ao mesmo tempo, ele constitui a mais implacável vindicação deste Nada como pura, absoluta, potencialidade" (AGAMBEN; DELEUZE, 1993, p. 87).

A partir da condição de desconectar-se, de estabelecer uma relação não mais com as estruturas montadas, pelos homens, para sobreviver, mas, ao contrário, de entrar em contato com o "outro lado", o dos mortos, o da gagueira, o do balbucio, o da falta, aquele onde a ordem falha e prevalece o vazio, Bartleby permite recuperar uma discussão que se ocupa do pensamento como cifra e da linguagem como pura potência, em relação a tudo o que, neles, escapa da totalização racional do sentido e faz retornar ao indefinível.

Espectralidade desdobrada, o cinema "sobrevive", descarnado, catatônico, nos interstícios que são cortes, recortes e montagens, no limiar de um visível que aponta, cada vez mais, aos limites de seu próprio fazer, a partir dos quais se postula a fuga da mensagem, o esvaziamento da ideia, supondo que as especificidades do meio mantêm juntas as disjunções entre o cinema e a literatura.

\section{REFERENCIAS}

AGAMBEN, Giorgio. Bartleby, or on contingency. In: Potentialities: collected essays in philosophy. Ed. and translated by Daniel Heller-Roazen. California: Stanford University Press, 1999.
; DELEUZE, Gilles. Bartleby, la formula della creazione. trad. Stefano Verdicchio Macerata: Quodlibet. 1993.

BADIOU, Alain. Pequeno manual de inestética. Trad. Marina Appenzeller. São Paulo: Estação Liberdade, 2002.

Imágenes y palabras. Escritos sobre cine y teatro. Selección de textos y prólogo Gerardo Yoel; traducción María del Carmen Rodríguez. Buenos Aires: Manantial, 2005. BENJAMIN, Walter. Magia e técnica, arte e política. Trad. Sergio Paulo Rouanet, 7. ed. São Paulo: Brasiliense, 1994.

DELEUZE, Gilles. Bartleby ou la formule. Paris: Flammarion, 1989.

Bartleby, ou a fórmula. In: Crítica e clínica. Trad. Peter Pál Pelbart. São Paulo: Ed. 34, 1997.

A imagem-tempo. Trad. Eloisa de Araujo Ribeiro. São Paulo: Brasiliense, 2005. MELVILLE, Herman. Collected prose. Seleção e notas Harrison Hayford. New York: The Library of America, 1984.

Contos de Herman Melville. Seleção, tradução e introdução de Olívia Krähenbüld. São Paulo: Cultrix, 1969.

Bartleby, o escriturário: uma história de Wall Street. Trad. Cássia Zanon. Porto Alegre: L \& PM, 2003.

VILA-MATAS, Enrique. Nunca voy al cine. Barcelona: alertes ediciones, 1982.

Bartleby \& compañía. Barcelona: Anagrama, 2000.

Recebido para publicação em 20 set. 2012. Aceito para publicação em 09 out. 2012. 